\title{
Characterization of Airport Movement Sequence
}

\author{
Bianka Károly², Balázs Sághi² \\ ${ }^{1}$ HungaroControl Ltd., H-1185 Budapest, Igló utca 33-35, Hungary \\ 2 Department of Control for Transportation and Vehicle Systems, Faculty of Transportation Engineering and Vehicle Engineering, \\ Budapest University of Technology and Economics, H-1111 Budapest, Műegyetem rkp. 3., Hungary \\ * Corresponding author, e-mail: bianka.karoly@hungarocontrol.hu
}

Received: 12 June 2019, Accepted: 08 July 2019, Published online: 14 December 2021

\begin{abstract}
Runways as the most critical parts in the aviation infrastructure have a great impact on the whole aviation effectiveness. Our present research has attempted to provide a better understanding of the nature of the sequence between the runway movements. For that traffic data of a typical medium-capacity airport was analyzed.
\end{abstract}

Keywords

airport movement, landing, departure

\section{Introduction}

Runways, as the most critical parts in the aviation network, are faced with increasing capacity demand. In addition, the new airspace users, the drones, are the most threatening to aircraft approaching or taking off from the airports. The sequence of the airport movements such as the take-off and landing provides a good indication of the runway load (Kling et al., 2017; Madácsi, 2015).

The distribution of the slot time issued to the aircraft movements is inefficient, entail unnecessary restrictions and uneven traffic density. In our view, one of the reasons for this is the lack of knowledge of the temporal distribution of operations. Namely, with the knowledge of distributions, the allocation of slots would be more efficient. In addition, knowing the real sequence of the departures and arrivals can also serve as a basis for the risk assessment of airports for the increasing unmanned aircraft traffic (Serhan et al., 2018).

\section{Methodology}

An analysis was carried out on the traffic data of a randomly selected summer schedule day at Budapest Liszt Ferenc International Airport. Fig. 1 illustrates the location of the airport's runways and their movement directions. The runways make possible 8 different movement directions.

The assessed elementary event was the time sequence between the arriving and departing movements per runway directions which can be considered a discrete variable.

\subsection{Boxplot analysis}

Boxplots are a standardized way of displaying the distribution of data based on a five number summary, which are:

- minimum,

- first quartile $\left(Q_{1}\right)$

- median,

- third quartile $\left(Q_{3}\right)$ and

- maximum.

The boxplot (Fig. 2) displays the full range of variation (from min to max), the likely range of variation interquartile range (IQR) which is the range of the variation from the $Q_{1}$ to the $Q_{3}$. The median represents a typical value of the distribution. Boxplot also visualizes the surprisingly

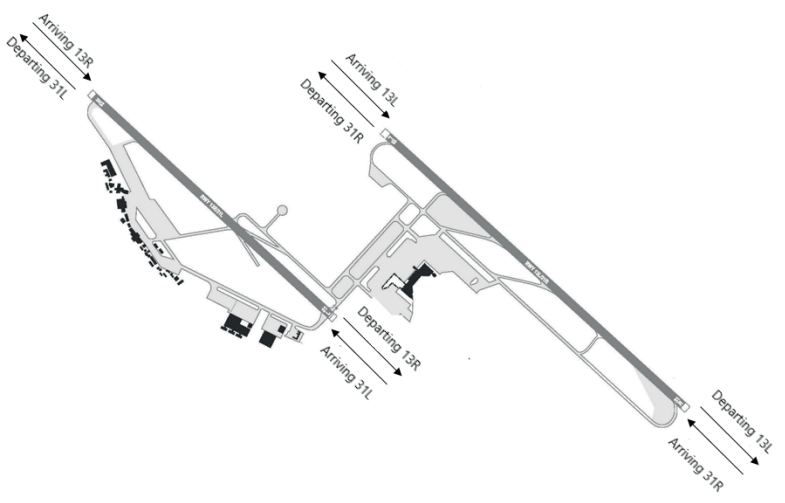

Fig. 1 Directions of landing and take-off at Budapest Liszt Ferenc International Airport 


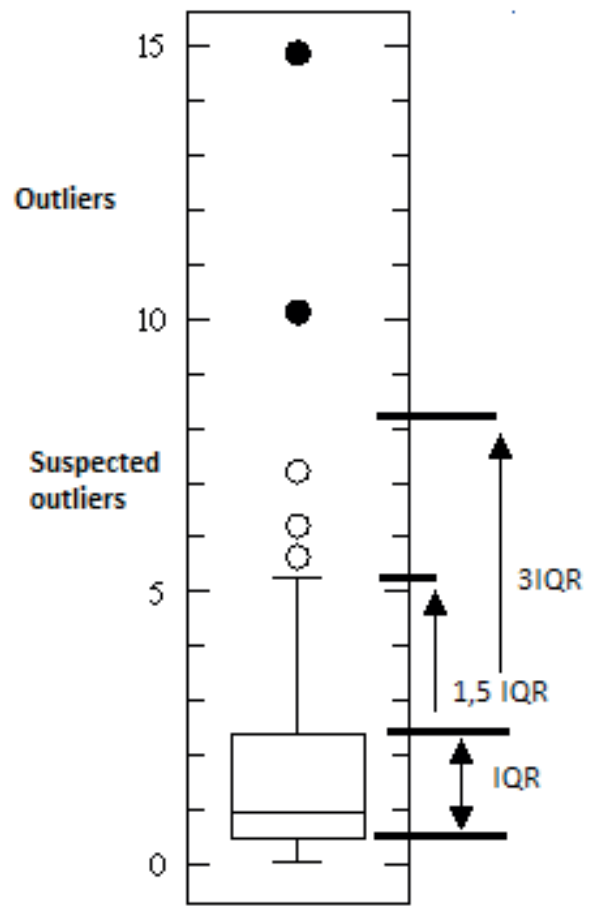

Fig. 2 Interpretation of boxplot diagram

high or surprisingly low values called outliers. Two types of outliers can be distinguished:

- Suspected outliers that are either $1.5 \times \mathrm{IQR}$ or more above the $Q_{3}$ or $1.5 \times$ IQR or more below the $Q_{1}$ :

$$
\begin{aligned}
& x_{i}<Q_{1}-1.5 \mathrm{IQR} \\
& x_{i}>Q_{3}+1.5 \mathrm{IQR} .
\end{aligned}
$$

- Outliers are either $3 \times \mathrm{IQR}$ or more above the $Q_{3}$ or $3 \times$ IQR or more below the $Q_{1}$ :

$$
\begin{aligned}
& x_{i}<Q_{1}-3 \mathrm{IQR} \\
& x_{i}>Q_{3}+3 \mathrm{IQR} .
\end{aligned}
$$

The outliers could be values that are associated with abnormal, one-time events or special cases. These could have a great, unwanted influence on the final results of the analysis. Therefore, it was important not to take them into consideration and therefore the outliers were removed from the sample (Čavka et al., 2016).

\subsection{Poisson distribution}

In our study, we investigate whether the frequency of the measured time sequences could have been modelled with Poisson distribution the lambda $(\lambda)$ parameter of which is the mean value of the time sequence.
The function of the Poisson distribution is:

$$
P_{k}(t)=\frac{(\lambda t)^{K}}{K !} e^{-\lambda t},
$$

where

- $P$ is the probability of an aircraft departure or arrival $(k=0,1,2, \ldots)$ within a short $t$ time,

- $\lambda$ parameter is estimated with the mean value of the sample.

\subsection{Chi-square goodness of fit test}

For the justification of our hypothesis Chi-square goodness of fit test was conducted. Chi-Square goodness of fit test is a non-parametric test that is used to find out whether the distribution of the observed value could be fitted with the expected Poisson distribution the $\lambda$ parameter of which is the mean of the observed sample. For the calculation of the value of Chi-Square goodness of fit test the following Pearson's formula was used:

$\chi_{\text {calc }}^{2}=\sum_{i=1}^{n} \frac{\left(O_{i}-E_{i}\right)^{2}}{E_{i}}$,

where:

- $\chi_{\text {calc }}^{2}=$ Calculated Chi-Square goodness of fit test,

- $O=$ observed value

- $E=$ expected value.

The null hypothesis $\left(H_{0}\right)$ assumes that there is no significant difference between the observed and the expected value, while, the alternative hypothesis $\left(H_{1}\right)$ assumes that there is a significant difference between the observed and the expected value:

- $\chi_{\text {calc }}^{2}<\chi_{\text {krit }}^{2}: H_{0}$ is accepted,

- $\chi_{\text {calc }}^{2}>\chi_{\text {krit }}^{2}: H_{1}$ is accepted.

The prerequisite of this test is that for each class the value of the expected frequency should be at least 5 . If this is not the case, the value of the degree of freedom must be reduced by the number of the merged classes. The degree of freedom is:

$d f=k-p-1$

where:

- $k$ : the number of classes with at least 5 frequencies,

- $p$ : the number of the estimated parameters.

The value of $\mathrm{k}$ is decreased by the number of classes with less than 5 frequencies since these classes were merged together. In this particular case, the value of $p=1$, while only the lambda was estimated with the 
average of the sample (Čokorilo et al., 2013; Madácsi, 2015; Moretti et al., 2018; Sipos, 2017).

\section{Results}

On the chosen day, 354 aircraft movements (take-off and landing altogether) were recorded in total. To analyze the statistical population, these movements were separated by runway directions and by the type of movements. In theory, the 4 runway direction and 2 movement types (departing and arriving) would result in 8 different research opportunities:

- Arriving 13R,

- Arriving 13L,

- Arriving 31R,

- Arriving 31L,

- Departing 13R,
- Departing 13L,

- Departing 31R,

- Departing 31L.

However, the arrival to the runway $13 \mathrm{~L}$ was prohibited at the airport on the day examined, so there was no data available about that case. With regard to $13 \mathrm{R}$, only one arrival took place meaning that the time sequence was not interpretable. Thus, we conducted the investigation on a total of six measured data sets.

Based on the sample sizes (Table 1), it can be concluded that the wind supported the use of direction (31), since 31R was used for arrival and 31L for departure (Table 2).

The boxplot diagrams in Fig. 3, in all but one case, revealed a number of suspected outliers. Out of these,

Table 1 Sample sizes of runways

\begin{tabular}{|c|c|c|c|c|c|c|}
\hline & Arriving $13 \mathrm{R}$ & Arriving $31 \mathrm{~L}$ & Arriving 31R & Departing 13L & Departing 31R & Departing 31L \\
\hline Sample size & 4 & 16 & 156 & 16 & 27 & 128 \\
\hline & Arriving 13R & Arriving $31 \mathrm{~L}$ & Arriving 31R & Departing 13L & Departing 31R & Departing $31 \mathrm{~L}$ \\
\hline$P_{k}(t)$ & 0.123 & 0.762 & 0.079 & 0.762 & 0.9273113 & 0.1340077 \\
\hline$d f$ & - & 1 & 9 & 1 & 1 & 7 \\
\hline$\chi_{\text {calc }}^{2}$ & - & 9.5979 & 2.343826 & 9.597569 & 65.68005 & 1.022583 \\
\hline$\chi_{k r i t}^{2}$ & - & 3.8419 & 16.91898 & 3.841459 & 3.841459 & 14.06714 \\
\hline Accepted hypothesis & - & $H_{1}$ & $H_{0}$ & $H_{1}$ & $H_{1}$ & $H_{0}$ \\
\hline
\end{tabular}
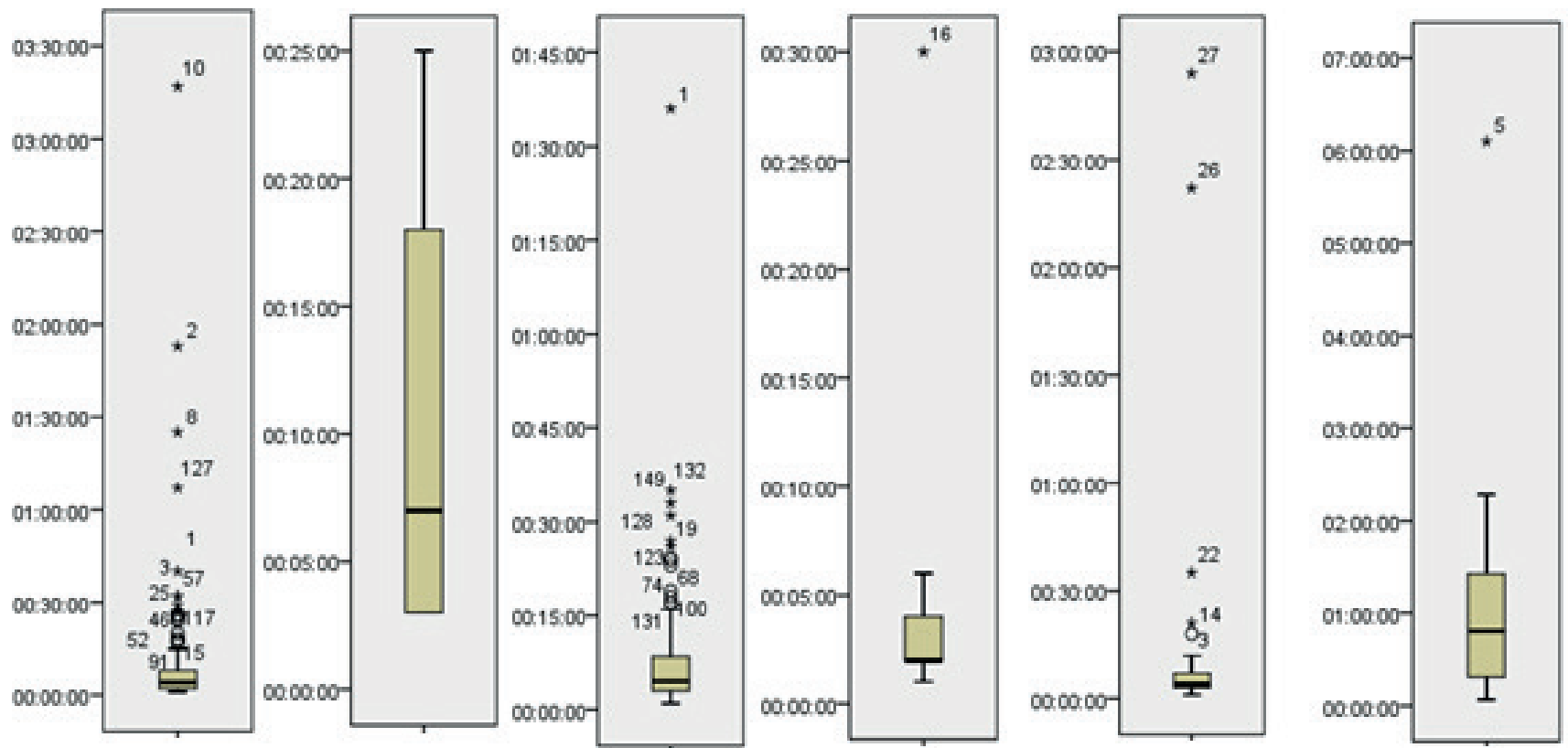

Departing 31 
Table 3 The descriptive statistics of the filtered data

\begin{tabular}{|c|c|c|c|c|c|c|}
\hline & Arriving 13R & Arriving 31L & Arriving 31R & Departing 13L & Departing 31R & Departing $31 \mathrm{~L}$ \\
\hline Expected value & $0: 10: 30$ & $0: 52: 00$ & $0: 05: 33$ & 0:02:44 & 0:04:05 & $0: 04: 38$ \\
\hline Median & 0:07:00 & 0:47:00 & 0:04:00 & 0:02:00 & 0:03:00 & 0:03:00 \\
\hline Mode & \multicolumn{2}{|c|}{ N/A } & 0:03:00 & 0:02:00 & 0:03:00 & 0:02:00 \\
\hline Std Dev & $0: 10: 23$ & $0: 40: 54$ & 0:03:36 & $0: 01: 37$ & 0:02:29 & 0:03:32 \\
\hline Kurtosis & 1.030931 & -0.0819197 & 1.0443446 & 0.5653814 & 3.6889793 & 3.9869908 \\
\hline Skewness & 1.31581682 & 0.8669360 & 1.2998358 & 1.30470731 & 1.7059694 & 1.8941196 \\
\hline Range & 0:22:00 & 2:13:00 & 0:16:00 & 0:05:00 & 0:11:00 & 0:17:00 \\
\hline Minimum & 0:03:00 & 0:04:00 & 0:01:00 & 0:01:00 & 0:01:00 & 0:01:00 \\
\hline Maximum & 0:25:00 & $2: 17: 00$ & $0: 17: 00$ & 0:06:00 & 0:12:00 & 0:18:00 \\
\hline Count & 4 & 15 & 145 & 15 & 22 & 114 \\
\hline
\end{tabular}

Table 4 Chi square tests results

\begin{tabular}{lcccccc}
\hline & Arriving 13R & Arriving 31L & Arriving 31R & Departing 13L & Departing 31R & Departing 31L \\
\hline Distribution & N/A & not Poisson & Poisson & not Poisson & not Poisson & Poisson \\
\hline
\end{tabular}

for the departing $31 \mathrm{~L}$ and the arriving $31 \mathrm{R}$ the number of outliers and suspected outliers are outstandingly high. The left side asymmetry is further evidenced by the boxplot charts, as none of them exhibits any low outliers.

The extreme values found by the boxplots were filtered out from the dataset (Table 3). The results of the Chi-square goodness of fit test of the Poisson function are presented in Table 4.

\section{Conclusion}

The analyses showed that the traffic in the direction of 31 was $81 \%$ of the total traffic of the airport. This $81 \%$ was divided between the departing $31 \mathrm{R}$ and arriving $31 \mathrm{~L}$.

\section{References}

Čavka, I., Čokorilo, O., Vasov, L. (2016) "Energy efficiency in aircraft cabin environment: Safety and design", Energy and Buildings, 115, pp. 63-68.

https://doi.org/10.1016/j.enbuild.2015.01.015

Čokorilo, O., Mirosavljević, P., Vasov, L., Stojiljković, B. (2013) "Managing safety risks in helicopter maritime operations", Journal of Risk Research, 16(5), pp. 613-624. https://doi.org/10.1080/13669877.2012.737828

Kling, F., Somosi, V., Pokorádi, L., Rohács, D. (2017) "Budapest Liszt Ferenc Nemzetközi Repülőtér légijármű forgalmának elemzése Markov-folyamatokkal" (Budapest Liszt Ferenc International Airport Aircraft Traffic Analysis with Markov Processes), Repüléstudományi Közlemények, 29(3), pp. 115-126. (in Hungarian)

Madácsi, R., (2015) "Data science technikák alkalmazása a futópálya-hatékonyság növelésében" (Applying data science techniques to increase runway efficiency), Repüléstudományi Közlemények, 27(3), pp. 159-170. (in Hungarian)
The Chi-square goodness of fit test supported our hypothesis that these follow Poisson distribution (Table 4).

The other runway operations did not show Poisson distribution. Our investigation revealed the reason for that which is the small size of the samples.

It can be stated, the larger the sample size, the closer the time sequence of the arrival and departure to Poisson distribution. Our hypothesis is correct since Poisson distribution was found to the larger sample sizes datasets. Our assessment method can serve as an appropriate basis for conducting further air traffic distribution analysis.

Moretti, L., Di Mascio, P., Nichele, S., Cokorilo, O. (2018) "Runway veeroff accidents: Quantitative risk assessment and risk reduction measures", Safety Science, 104, pp. 157-163. https://doi.org/10.1016/j.ssci.2018.01.010

Serhan, D., Lee, H., Yoon. S. W. (2018) "Minimizing airline and passenger delay cost in airport surface and terminal airspace operations", Journal of Air Transport Management, 73, pp. 120-133. https://doi.org/10.1016/j.jairtraman.2018.07.001

Sipos, T. (2017) "Spatial Statistical Analysis of the Traffic Accidents", Periodica Polytechnica Transportation Engineering, 45(2), pp. 101-105. https://doi.org/10.3311/PPtr.9895 